\title{
INFECTED ABDOMINAL AORTIC GRAFTS
}

\author{
Mohammad Yahya Al-Shehri, FRCSC; Neil V. McPhail, MD, FRCSC; Graeme Barber, MD, FRCSC; \\ Isaac Grillo, MD, FACS, FACA; Abdulatif A. Softah, FRCSC
}

\begin{abstract}
Aortic grafts were inserted in 1711 patients at Ottawa Civic Hospital (OCH) between 1976 and 1986. Aorto-iliac occlusive disease was the indication in 884 while in 827 , the graft was inserted for abdominal aortic aneurysms. Graft infection occurred in 12 patients; six presenting with gastrointestinal bleeding due to aorto-enteric fistula (AEF) and the other six presenting with groin abscesses, mostly as a draining sinus. These were treated with graft excision and immediate extra-anatomic bypass. Seven patients died, giving a mortality rate of $58 \%$. Three surviving patients required above-knee amputation. These results are comparable to the results of others in the literature; therefore, continuing assessment of all aspects of graft infection and the search for more effective methods of prevention and management are needed. Ann Saudi Med 1994;14(4):304-306.
\end{abstract}

The profound consequences of prosthetic graft infection are of major concern in vascular surgery. The incidence of graft infection is reported to be $0.2 \%$ to $2 \%$ for aortic grafts and up to $6 \%$ for femoro-popliteal graft. ${ }^{1,2}$ The mortality rate of aortic graft infection was reported in early reports to be up to $75 \% .^{3}$ The mortality rate is still reported in recent papers as ranging between $40 \%$ and $60 \% .^{4-6}$ Infected aortic grafts cause a high morbidity that includes limb loss of between $20 \%$ and $37 \% .^{6-11}$ Recently, some reports have advocated in situ insertion after removal of the infected grafts, ${ }^{12}$ while others stage the procedure by performing the extra-anatomic bypass first. ${ }^{9,10,13,14}$ We reviewed our experience in Ottawa Civic Hospital $(\mathrm{OCH})$ to assess our infection, mortality and morbidity rates.

\section{Material and Methods}

This study is a review of 10 years' experience in Ottawa Civic Hospital between the years 1976 and 1986. Aortic grafts were inserted in 1711 patients. The indications are shown in Table 1. All patients received antibiotics one hour preoperatively, consisting of first generation cephalosporin. The antibiotics were continued until all the hemomonitoring lines and Foley catheters were removed. Preparation of the operation site was performed using a razor blade on the operating table. Plastic drapes were routinely used. Great care was taken in mobilizing the duodenum. The mural thrombus and debris were removed,

From the Department of Surgery (Drs. Al-Shehri, Grillo, Softah), King Saud University, Abha Branch, College of Medicine, Abha and Division of Vascular Surgery (Drs. McPhail and Barber), Ottawa Civic Hospital, Ottawa, Ontario, Canada.

Address reprint requests and correspondence to Dr. Al-Shehri: Department of Surgery, King Saud University, Abha Branch, College of Medicine, P.O. Box 641, Abha, Saudi Arabia. Accepted for publication 6 September 1993. leaving the posterior wall intact, and the retroperitoneum was closed carefully. Wound lavage with bacitracin was performed in all these cases.

\section{Results}

Graft infection occurred in 12 patients, seven of whom died, giving a mortality rate of $58 \%$. Graft sepsis presented with gastrointestinal bleeding due to aortoenteric fistula (AEF) in six patients. The bleeding was mild to moderate and intermittent in all patients. Melena occurred in all of these patients and was accompanied by hematemesis in only one patient. The other six patients presented with groin abscesses, usually as a draining sinus. One of the patients was explored for a groin mass, at which time the graft was found floating in pus.

Graft infection occurred in the first postoperative year in three patients. One patient presented with symptomatic abdominal aortic aneurysm and on dissecting his duodenum, he was found to have a small inadvertent enterotomy, which was repaired in two layers, and omentum was interposed between it and the graft. The retroperitoneum was then closed over the graft. This patient presented within three weeks with aortoduodenal fistula with general signs of sepsis and died due to sepsis after resection of his graft and construction of an extraanatomical bypass. Four patients presented in the second and third years postoperatively, while three patients

TABLE 1. Indications for inserting aortic grafts.

\begin{tabular}{lrc}
\hline & \multicolumn{2}{c}{ Patients } \\
Indications & No. & $\%$ \\
\hline Abdominal aortic aneurysms & 827 & 48.3 \\
Aorto-iliac occlusive disease & 884 & 51.6 \\
Total & 1711 & 100 \\
\hline
\end{tabular}


TABLE 2. Duration of period between aortic graft and infection.

\begin{tabular}{lcc}
\hline Duration (years) & No. & $\%$ \\
\hline 1 & 3 & 25 \\
$2-3$ & 4 & 33 \\
$4-6$ & 3 & 25 \\
$7-8$ & 2 & 17 \\
Total & 12 & 100 \\
\hline
\end{tabular}

TABLE 3. Extent of involvement of prosthesis and outcome.

\begin{tabular}{lccc}
\hline Site of Graft Placement & $\begin{array}{c}\text { Extent of } \\
\text { Involvement }\end{array}$ & $\begin{array}{c}\text { No. of } \\
\text { Patients }\end{array}$ & $\begin{array}{c}\text { No. of } \\
\text { Deaths }\end{array}$ \\
\hline Aortic-iliac & Shaft & 4 & 3 \\
Aorto-femoral & One limb & 0 & 0 \\
& Shaft & 5 & 3 \\
Total & One limb & 3 & 1 \\
\hline
\end{tabular}

presented between the fourth and sixth years. Only two patients acquired graft infection after the seventh year postoperatively (Table 2).

Two-thirds of the infected grafts were aorto-femoral in location and the other one-third were aorto-iliac. The extent of graft involvement is shown in Table 3. Organisms were cultured from the grafts in 11 patients, one or more species of gram-positive organisms having been cultured from four patients. Mixed gram-positive and gram-negative organisms were found in four patients and gram-negative organisms were cultured in three patients. No bacterium was cultured in one patient.

White blood cells were mildly elevated in seven patients and normal in five. Fever was present in seven patients and was within normal limits in the others.

Endoscopy to diagnose the cause of the gastrointestinal bleeding was performed in all of the six patients. No cause of the bleeding was found in four of these patients. Diagnosis of gastric erosions was established in one patient. In only one patient was the diagnosis determined after the endoscopist was alerted to the possibility. Computed tomography (CT) scan was done in two patients and showed the abscess around the graft in both patients. Arteriography was done in three patients and was not helpful in any of them.

\section{Management and Outcome}

Conservative management including intravenous antibiotics failed to eradicate graft infection in any patients. Resection of the graft was performed. Closure of the aortic stump was established with monofilament nonabsorbable material and this was reinforced with an omental patch in all patients. The duodenum was closed in two layers in the six cases of AEF and omentum was interposed between the duodenum and the aortic stump. The abdomen was then closed. After redraping the patient and changing the instruments, an extra-anatomical bypass between the axillary artery and the femoral artery was done. If the area of the femoral artery was contaminated, the popliteal artery was used.

Seven patients died during the same hospitalization; five of these patients died due to sepsis. Two patients died of bleeding from the aortic stump. Two surviving patients required bilateral above-knee amputation. Another patient required above-knee amputation of his right leg. The extraanatomical graft became infected in four patients including those who required amputation. Only one patient was still walking on both legs with no sign of infection after four years of follow-up.

\section{Discussion}

Infection of the graft occurred in five patients of the abdominal aortic aneurysm group and in seven patients of the aorto-iliac occlusive disease group. These numbers are too small to permit statistical analysis. The overall infection rate is $0.7 \%$, which is an improvement over the same institution's previous experience of $2.7 \%$. $^{1}$

Staphylococcus aureus, Staphylococcus epidermidis, E. coli, and Klebsiella were the most common organisms cultured. This compared with a previous report from the same institution, although Staphylococcus epidermidis was not cultured from the graft in the previous report. ${ }^{1}$ The predominance of gram-positive organisms in our study is in agreement with others ${ }^{15}$ and this raises the possibility of skin-originating contamination. Therefore, the use of an antibiotic that would cover both gram-positive and gramnegative organisms is advisable prior to culture results.

Preoperative diagnostic studies including arteriography have a low yield in the majority of patients with aortic graft infection. CT scan confirmation of a paraprosthetic enteric fistula has been found to be useful by others, ${ }^{16}$ as we found in two of our patients. We did not use scintigraphic detection of abscess with indium-111-labeled leucocytes as reported by some. ${ }^{17}$

Despite aggressive surgical treatment with graft resection and extra-anatomical bypass, seven patients died, giving a mortality rate of $58 \%$. This is within the range of mortality rate reported in the literature. ${ }^{3-6}$ We did not attempt the use of povidone-iodine irrigation to control the infection as advocated by some in the literature. ${ }^{12}$ Our amputation rate was also comparable to that reported in the literature..$^{6-11}$

Walker et al. ${ }^{18}$ have recommended in situ grafting for secondary aorto-enteric fistula. They had $22 \%$ hospital mortality rate and 16 out of the 18 surviving patients were alive after five years of follow-up, but it is worth noting that when the graft was inserted in the presence of 
paraprosthetic graft infection, $60 \%$ of patients died. Their experience and those of others ${ }^{19}$ suggest that this procedure may be safe in selected cases.

The performance of the extra-anatomical bypass graft prior to graft removal is preferred by some. ${ }^{9,10,13,14}$ This has the advantage of giving the surgeon more time to perform the abdominal procedure without worrying about the ischemic time of the lower limbs. This sequence has the theoretical disadvantage of increasing the incidence of the extra-anatomical graft infection, but this is not supported by studies in the literature. 9,10

In conclusion, we feel that prevention is the most important measure to deal with this lethal complication. Once the diagnosis of an infected graft is made, early graft excision and prompt revascularization are required. In situ graft insertion has a satisfactory result in secondary aortoenteric fistulae in the absence of paraprosthetic abscesses. We did not use local debridement and irrigation and we believe that their use should await more convincing evidence.

\section{References}

1. Scobie TK, Elder RH, McPhail N. Infected abdominal aortic grafts. Can J Surg 1978;21:527-31.

2. Szilagyi DE, Smith RF, Elliott JP, et al. Infection in arterial reconstruction with synthetic grafts. Ann Surg 1972;176:321.

3. Fry WJ, Lindenauer SM. Infection complicating the use of plastic arterial implants. Arch Surg 1967;94:600-9.

4. Jamieson GG, DeWeese JA, Rob CG. Infected arterial grafts. Ann Surg 1975;181:850-2.
5. Turnipseed WD, Berkoff HA, Detmer DE, et al. Arterial graft infections: delayed versus immediate vascular reconstruction. Arch Surg 1983;118:410-4.

6. Martin-Paradero V, Busuttil RW, Dixon SM, et al. Fate of aortic graft removal. Am J Surg 1983;146:194-7.

7. Goldstone J, Moore WS. Infection in vascular prosthesis: clinical manifestations and surgical management. Am J Surg 1974;128:22533.

8. Fulenwider JT, Smith RB, Johnson RW, et al. Reoperative abdominal arterial surgery - a ten year experience. Surgery 1983;93:20-7.

9. O'Hara PJ, Hertzer NM, Beven EG, et al. Surgical management of infected abdominal grafts: review of a 25 year experience. J Vasc Surg 1986;3:725-31.

10. Reilly LM, Stoney RJ, Goldstone J, et al. Improved management of aortic graft infection: the influence of operation sequence and staging. J Vasc Surg 1987;5:421-31.

11. Yeager RA, Moneta GL, Taylor LM, et al. Improving survival and limb salvage in patients with aortic graft infection. Am J Surg 1990;159:466-9.

12. Knight CD Jr, Farnell MB, Hollier LH. Treatment of aortic graft infection with povidone-iodine ionization. Mayo Clinic Proc 1983;58:472-5.

13. Elliott JP, Smith RF, Szilagyi DE. Aorto-enteric and paraprostheticenteric fistulas. Arch Surg 1974;108:479-90.

14. Yeager RA, McConnell DB, Sasaki TM, et al. Aortic and peripheral prosthetic graft infection: differential management and causes of mortality. Am J Surg 1985;150:36-43.

15. Ricotta JJ, Faggioli GL, Stella A, et al. Total excision and extraanatomic bypass for aortic graft infection. Am J Surg 1991;162:145-9.

16. Higgins RSD, Steed DL, Zajko AB, et al. Computed tomographic scan confirmation of paraprosthetic enteric fistula. Am J Surg 1991;162:36-8.

17. Scabold JE, Wilson DB, Lieberman LM, Boyd CM. Unsuspected extra-abdominal sites of infection: scintigraphic detection with indium-111-labeled leucocytes. Radiology 1984;151:213-7.

18. Walker WE, Cooley DA, Duncan JM, et al. The management of aortoduodenal fistula by in situ replacement of the infected abdominal aortic graft. Ann Surg 1987;205:727-32.

19. Thomas WEG, Baird RN. Secondary aorto-enteric fistulae: towards a more conservative approach. Br J Surg 1986;73:875-8. 